
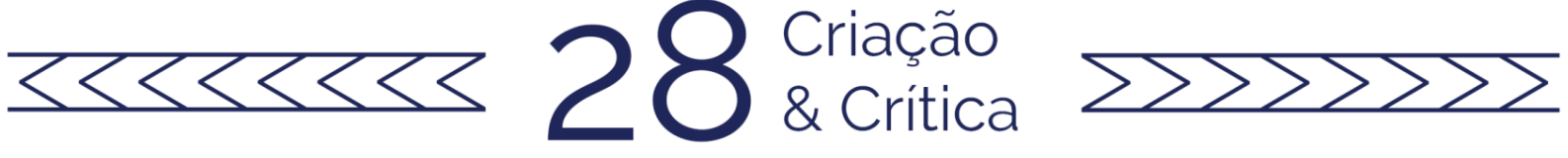

\title{
ROSAS EN REBÉTIKO, UNA OPERA APERTA: CONSTRUCCIÓN DE SUBJETIVIDADES DE GÉNERO EN OASIS (2020) DE DANIEL MELINGO1
}

Cynthia Carggiolis Abarza ${ }^{2}$

Resumen: El presente trabajo analiza la construcción de las subjetividades de género heteronormativas arrastradas por una red construida a través de la identidad cultural del Linyera (2014) y de la tripulación marítima intermedial e intertextual propuestas en las letras de Oasis (2020) de Daniel Melingo. Desde la imagen del navío y de las subjetividades de género se avistan irradiaciones de figuras (des)mitificadas cuyos textos y personajes se ven amarrados a la leyenda porteña de El Linyera. En su función poética transmite diversas sonoridades y redes textuales orales que configuran una ópera en rebétiKo, en las profundidades laberínticas del tango como manifestación poético-cultural con características marinas.

PALABRAS CLAVE: Oasis, tango-rebétiko, navegantes, subjetividades de género.

\section{ROSAS IN REBÉTIKO, UNA OPERA OPERA: CONSTRUCTION OF GENDER SUBJECTIVITIES IN OASIS (2020) BY DANIEL MELINGO}

ABSTRACT: This article analyses the construction of the heteronormative gender subjectivities that are weighed by a network built through the cultural identity of Linyera (2014) and the intermediate and textual maritime crew proposed in the lyrics of Oasis (2020) by Daniel Melingo. In the image of the ship and gender subjectivities, exposures of (de)mythologized figures, whosetexts and images are tied to the Buenos Aires legend of El Linyera, are sighted. In its poetic function, El Linyera transmits various sounds and oral textual networks thatmake up an opera in RebetiKo, in the labyrinthine depths of tango as a poetic-cultural manifestation with navy characteristics.

KEYWORDS: Oasis, tango-rebétiko, navigators, gender subjectivities.

\section{Introducción: Défense de la creatividad poética en Oasis(2020)}

"Es indudable que, más allá de los sistemas tonales, existe en la música un código que regula las relaciones de los sonidos entre ellos, dado que estas relaciones son representadas en términos de metalenguaje matemático". [...] El músico es el teórico de la música el conocedor de las leyes musicales, de las leyes matemáticas que gobiernan el mundo sonoro. (ECO, 2009, p. 16)

\footnotetext{
${ }_{1}^{1}$ Agradezco a Daniel Melingo por su acotaciones, cordial y profesional colaboración en el afinamiento de este artículo. De igual modo, mis agradecimientos van por el rápido envío de material, por haberme contactado con el maestro de lunfardo, el Dr. Luis Alposta y con el diseñador gráfico Ricardo Mosner. Asimismo mis agradecimientos a Marcia Jimenez y a Tracey Kimmeskam por la corrección, al curador chileno Rolando Báez por compartir el gusto del Melingo-tango.

${ }^{2}$ Investigadora independiente, doctoranda de la Ruhr-Universität Bochum, Germany (2020); contacto: carggcbe8@gmail.com.
} 

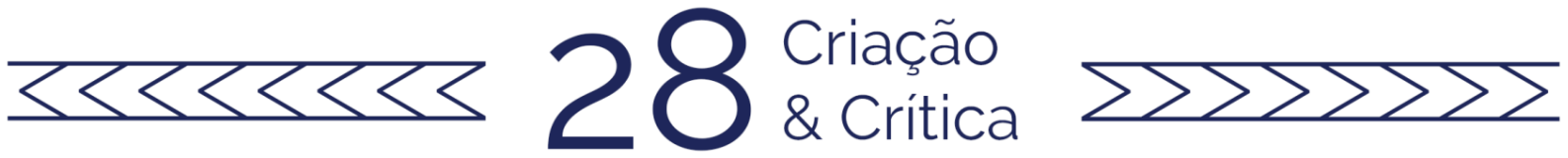

El inicio de la relación matemática y musical como opera aperta sugiere la antigua relación elemental entre teorías estéticas y matemáticas. Eco menciona esta vinculación con objeto de establecer un límite dentro de este mismo dédalo pitagórico, mas utiliza en La soglia e l'infinito (2007) los límites de la teoría de los fractales para ser analizados en abyme a través de la construcción de una enciclopedia infinita con paradigmas ligados a la deconstrucción en la que los textos se adhieren a otras formas artísticas a las musicales, pictóricas, teatrales, o bien, a las (audio)visuales (ECO, 2009, pp. 8-26). En este caso particular, se muestra en Oasis (2020) una fusión de tango-canción, milonga lenta, blues, tango-deep, poesía, arte, cine, teatro y producción audiovisual a partir de la noción de opera aperta, bajo el síndrome de "vértigo del laberinto", de la transgresión de las tonalidades hacia 1919 (12 en apuesta vanguardista). Sin embargo, casi cien años más tarde la apuesta postvanguardista de Oasis consta de 13 ciclos de música y letras musicalizadas bajo la figura retórica-cultural de El Linyera, ${ }^{3}$ con espera de proyección hacia 42 más que componen su opera aperta 4 .

Desde el punto de vista lingüístico, Oasis (2020) apunta a una isla con vegetación rodeada de agua, a un espacio idílico en tiempos de austeridad, de crisis, de globalización y de una serie de eventos inesperados y catastróficos ocurridos en las temporalidades pulverizadas por el retorno de las profundas sonoridades de identidad del tango parangonado con el rebétic[k] $\mathrm{O}^{5}$ y con puntos de convergencia de géneros contemporáneos como el jazz. En consonancia con el rebétiko de Melingo (2020), el sonido obstruyente de la consonante griega $k$, no sólo dificulta el paso del aire sino más bien pone en escena el clarinete que dirige el navío familiar en el proyecto multifacético Oasis (2020). La letra $\boldsymbol{k}$ conincide de manera visual por su forma entrecortada con el dibujo, que construye el motivo de la carátula en tinta, la imagen negra del disco, en tanto una "danza inmóvil" (PIZARNIK, 2015 , p. 75$)^{6}$. Esta imagen recta sin mayor adorno diseñada por Ricardo Mosner revive a El Linyera: sombrero negro de copa, saco negro, zapatos negros estragados, al transhumante y la idea del trasladado de quien maneja historias orales. En Oasis (2020) se amarran las historias de las figuras que representan la ópera.

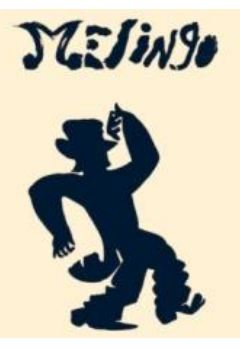

® Ricardo Mosner, El Linyera (2020).

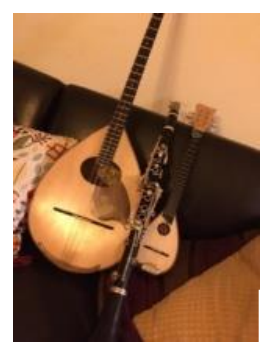

(B) Daniel Melingo (2020).

\footnotetext{
${ }^{3}$ La idea de figura retórica abraza la historia circular un futuro-pasado de este personaje.

${ }^{4}$ Remito estas observaciones al trabajo en colaboración con Melingo por vía electrónica, fecha: marzo-mayo 2020.

${ }^{5}$ Aprovecho la dualidad de las letras $c / k$ para acentuar el origen griego del "rebético" emparentado con el "tango".

${ }^{6}$ Pizarnik mantiene la figura en movimiento que, de modo análogo, dialoga con lo expuesto arriba en el poema "La danza inmóvil" de La tierra más ajena (1955) anunciando esto desde la oscuridad (PIZARNIK, 2015, p. 75).
} 

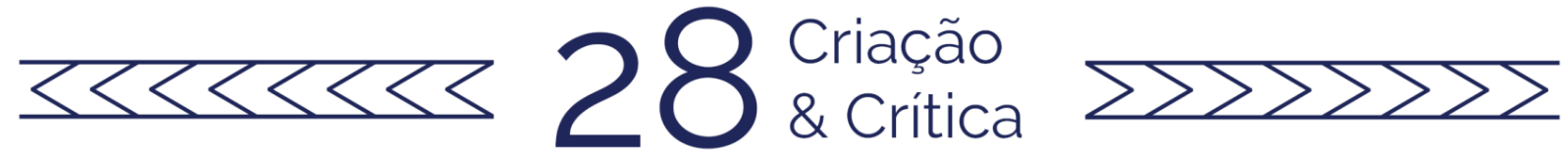

El tango, a partir del rebétiKo, reaparece siendo una apuesta oceánica, de origen marinero de Oriente a Occidente con acentos y sonidos orientales. Asimismo estas sonoridades incitan la entrada de un dédalo interno que armoniza la búsqueda de lo propio en diálogo con los principios budistas iniciados ya en los noventa, producido en tiempos del que cada uno migrante interno. Con ello se le da a la ruptura de la vanguardia hacia 1920 un acento paraKultural de Centenario en 2020, la actualiza y proyecta lo criollo-bohemio argentino, en tanto bastardo, lo globaliza y lo denomina gótico rioplatense ${ }^{7}$ bajo el amparo de las letras vanguardistas de Isidore Ducasse, el Conde Lautréamont, y sus Los cantos de Maldoror, no obstante la propuesta de Melingo se sitúa en la directriz del neobarroco (GRAZIANO, 2020; STRASSBURGER, 2020; PERLONGHER, 1997, p. 199; PUIG, 1996). Connota relaciones intertextuales en las letras del arrabal y de las diversas vinculaciones temáticas con anteriores producciones, como lo son Linyera (2014) y Anda (2016) cuyo objetivo es la de dar continuación a densas subjetividades protopoéticas que encarnan un complejo dédalo interno y telúrico/ tectonal nacido del ritmo de los pies, en las que el artista es mediador entre el mundo de su experiencia nocturna, el mundo fantasmal del barrio y el del mundo onírico desde el complejo ángulo de la vida contemporánea. Importancia del lunfardo en su estructura sintáctica y semántica, los cruces de un habla doméstica ${ }^{8}$, un habla social, un habla vulgar, un habla burocrática, un habla académica, se define bajo el amparo de una suma de tres vocabularios marginales: a) el gauchesco, campestre o rural, también presente en la literatura criolla; b) el cocoliche, el lenguaje acriollado de migrantes italianos llegados a fines del siglo XIX, un habla mixto especial y familiar, de profesiones y oficios, un jerigonza carnavalezco difícil de aprender; y c) el valesco (GOBELLO, 2006, pp. 28-34).

Alposta define el género tango como una alianza expresiva de melodía y palabra, poesía que parte de manera baudeliana de "la flor del dolor universal", se aparta de instituciones académicas, "[...] hablan del arrabal, del barrio, del cabaret, de la miseria, de la enfermedad, de la tristeza, de la bronca" (MELINGO, 2007). Así el habla lunfarda viene enredado en el mástil de los barcos, en aflorar de la plenitud de la pobreza y de la inequidad, en acontecimientos de la Fundación mítica de Buenos Aires (BORGES, 1977) que dependían del azar, nace en una trastienda rosada, en la bocacalle, en la proa que corta el agua, en los barquitos pintados, atravesando "[...] un mar que tenía cinco lunas de anchura/ y aun estaba poblado de sirenas y endriagos/ de piedras imanes que enloquecen la brújula" (BORGES, 1977, p. 95). Desenraizar el substrato mítico de los paradigmas del lunfardo neobarrocas, y reciclarlo hacia el terreno de lo popular globalizado a través de las nuevas sensibilidades de la megalópolis mediática con ayuda

\footnotetext{
${ }^{7}$ Strassburger sostiene una nutrida argumentación de lo "gótico rioplatense": "Definiría al gótico rioplatense como una estética y una sensibilidad cercana al dark contemporáneo que emana de la narrativa de Onetti, de ciertos tangos y de una experiencia vital que entrecruza a Buenos Aires y Montevideo" (STRASSBURGER, 2020).

${ }^{8}$ En Corazón \& Hueso (2011) encontramos marcas lingüísticas sostenidas en el lunfardo en el tango reo del letrista Dr. Luis Alposta en el que se avista un léxico extraido de lo doméstico: "A todos los internos/ crema les bate,/ a todos los internos/ crema les bate,/ y cuando se lo llama/ se lo obliga hacer cama y a cebar mate/ se lo obliga hacer cama y a cebar mate" (MELINGO, 2011).
} 

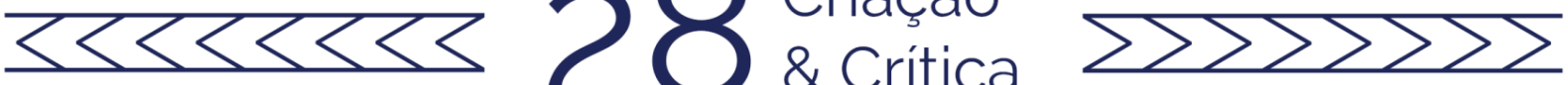

de dispositivos (re-ediciones del tango-canción con otros elementos añadidos, nuevas formas del lunfardo ${ }^{9}$ ). Del mismo modo, se reciclan los textos literarios, se habla de un Borges fractal, infinito, de espejos, de un neobarroso rioplatense de Boquitas pintadas dialogando con Pizarnik (OLALQUIAGA, 1992; PUIG, 1996) ${ }^{10}$.

\section{Semblanza proliferante marítima: Barquitos pintados}

La nave/ el barco como artefacto o dispositivo cultural, al igual que las letras de tango como estructuras poéticas (GASPARRI, 2011, p. 178; SOSA BACCARELLI, 2019, pp. 54-55), se define por ser el espacio donde circulan en el confín mundos imaginarios flotando, y por donde circulan discursividades políticas, visuales, intertextuales y afectivas de mundos planteados. En este imaginario marítimo van embarcados varios de los personajes de la opera en tres actos creada por Daniel Melingo en el disco Oasis (2020). Estos artefactos culturales no llevan sólo marcas intertextuales que arriban en la transformación de aparatos literarios de tradición clásica sino que estos mismos, a través de mecanismos de imitación, provocan reflexiones metodológicas, metódicas en un contexto y conocimiento histórico (KNAUTH, 1986/87, pp. 88-89). Desde este punto de vista, el barco, en su función simbólica cognitiva y en su dimensión icónica, resume un campo semántico caracterizado por un contexto sociocultural e histórico, en el caso de Oasis (2020), acorde a no distanciarse de la música nacional, de combinar el tango con "la lineyera" (de la "litoraleña"), trasportada en los barcos junto con el acordeón y ritmos de pueblos originarios (VITALE, 2014).

La imagen simbólica del navío en la tradición literaria transporta no sólo un lenguaje marítimo sino también a pasajeros, su historia, su vida (política, economía, social, técnica), y, al mismo tiempo, traslada el paradigma amoroso, religión, cultura (lengua, literatura, arte, música, filosofía). Además, moviliza la idea de la naturaleza, de la amenaza de vida y la imagen de la muerte, en tanto Barca de Caronte tematizada en Don Juan aux enfers de Baudelaire, al igual que el puerto de la muerte (KNAUTH, 1986/87, pp. 90-94) ${ }^{11}$. Esta última imagen, atiende a una tradición vinculada con la catástrofe, en principio, para el marinero ${ }^{12}$ que arriba a la costa esperada y contextualizada en la

\footnotetext{
${ }^{9}$ Las producciones mediáticas de reinterpretaciones del tango-canción proliferan de modo rizomático o paramedial/textual; se mantiene la vigencia de nuevas formas del tango y sus fusiones en Santa Milonga (2004), Corazón \& Hueso (2011), o bien, Maldito tango (2007).

10 Olalquiaga (1992) apunta a la latinización de Estados Unidos a través de los medios, acentúa la influencia de los medios como MTV, red por la cual también se registran entradas del trabajo musical Melingo. La estilística de lo cursi y de lo melodramático recodifica una estilística de la memoria mítica acuática de las orillas del río (OLALQUIAGA, 1992, p. 101).

11 El viaje iniciático del poeta, lleno de incidentes y peripecias, zarpa en los dédalos paisajísticos del Purgatorio, el poeta extrae: cieno, sangre, resina, arena, bosques, murallas de hierro oxidada (DANTE, 2014). Tanto La lliada y La Odisea prometen a la poesía remenderla sin alfabeto: el poeta, trovador, bardo o aedo crea obras de memoria, memoriando (HOMERO, 2012, pp. 9-12); y concede a la oralidad su debida importancia para efectos postvanguardistas porteños.

12 Lo marinero se tematiza la moda poco ortodoxa y barroca de Jean Paul Gaultier en el haute couture. Es el primero en crear la falda masculina y darle nueva vida al corsé. Esto se distancia de las formas geométricas,
} 

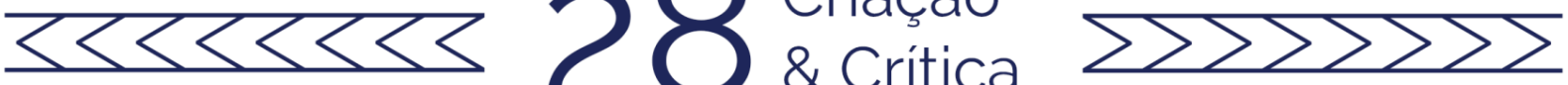

tradición literaria clásica por el género emblemático, en Baudelaire por el tema del viaje de la muerte en Le voyage (1857). La Barca de Caronte es interpretada en la vanguardia europea por Alberti en Nana del niño muerto del ciclo Marinero en tierra (1924), es expuesta como un canto a lo fúnebre y a lo precario (KNAUTH, 1986/87, p. 94) ${ }^{13}$. La imagen del niño doliente en el navío urbano, se esboza en Maldito tango (2007) acompañado de una "Oración para un niño criado en soledad; que muere sin haber conocido caricias ni besos. Que nunca recibió amor", la letra compuesta por Celeste Torres y Daniel Melingo, se titula: "Pequeño paria". Se narra el desamparo y el desconsuelo del sujeto infante como tópico temático en el género tanguero: "Pequeño paria el niño/ que de las sombras nació,/ juega el juego de la sangre/ para matar su dolor./ No conoce de alegrías/ de hielo es su corazón,/ de terror es su inocencia/ y de locura su amor.// Mamaste de ríos grises,/ la oscuridad te parió" (MELINGO, 2011). El sujeto infante no es un navegante, es un huacho urbano, nacido del desamparo, de la frialdad y de la oscuridad. La inequidad económica avista la construcción sociocultural de un postargentinazo, un pos-2001, mas recupera de modo nostálgico el período criollovanguardista argentino en manos de un aristocrático y elitista escritor. En el poema 1929 de Borges se habla del "modesto inquilino", se menciona: "[e]l hombre está mateando y esperando" quien "[v]e un diario abierto. Lee las grandes letras"; y anuncia "[c]risis ministeriales en países/ Que son apenas nombres" (BORGES, 1977, pp. 404-406) ${ }^{14}$. Del lado más popular, Arlt le da vuelta a la tuerca con su "mala escritura", postula a los efectos de la crisis económica de Wall Street, 1929, la Década infame o el Decantismo, el año del mundo de la radio-teatro, del mundo al revés, el de Los siete locos (1929) ${ }^{15}$.

El navío aborda del mismo modo, el tema de amantes, el barco cubre el tema del amor, del mundo de fantasía, de la diosa Fortuna, Venus, que navega por el Triángulo de las Bermudas en un océano bipartito de las pasiones entre lo dulce y lo amargo, entre lo frío y lo caliente ${ }^{16}$, entre la necesidad y la carencia, se navega por aguas de Eros

rectas y sencillas de estos trazos, y connota lo marinero al discurso parakultural del tango, del rebétiko, y de su pariente musical el fado en el desarrollo de la contracultura latinoamericana de los 80-90. Los avatares de lo literario con el rock, el fenómeno de la moda, la sensibilidad kitsch y el género del Arte andrógino. Estilo versus moda en un siglo corto (ECHEVARREN, 1998).

${ }^{13}$ En Nana del niño muerto (1924) se lee en Alberti: "Barquero yo de este barco/ sí, barquero yo.// [...]/ sí, barquero yo./ Rema, niño, mi remero/ No te canses, no.// Mira ya el puerto lunero,/ mira, miraló." (KNAUTH, 1986/87, p. 94). La imagen del niño, del adolescente y del joven se encuentran en la cultura popular del tango: un Lazarillo del arrabal, de padre a hijo: Melingo \& Félix Melingo.

${ }^{14}$ En Corazón \& Hueso (2011) aparece "Soneto a un malevo que no leyó Borges" de Dr. Luis Alposta, una propuesta planteada por el héroe urbano actual lejano de las reflexiones intelectuales de cánones: "No recibió la herencia del cuchillo/ [...]/ se enroló con modernos malevajes/ de inconciente con dedo en el gatillo." (MELINGO, 2011).

${ }^{15} \mathrm{El}$ tango-literatura arltiana posee una fuerte presencia kitsch de chafalonía; el lenguaje modelado por los folletines, el cotidiano y los nuevos géneros surgen en la década de los 30 el radio-teatro, una mezcla del triller con el radio-teatro y una utopia perversa (ARLT, 2011, pp. 11-75). Estos motivos reaparecen junto con la imagen materna tejiendo y el melodrama en Boquitas pintadas (PUIG, 1996).

${ }^{16} \mathrm{El}$ oxímoron - frío y caliente - resalta las áreas de los sentimientos, en amores pasionales cubiertos por el sufrimiento y el descontrol de las pasiones. Lo frío acentúa lo oscuro del conventillo, ambientes orilleros y del tango en el siglo XIX, en plena belle époque, próximos a Silvina Ocampo y a lo criollo-victorianobastardo. 

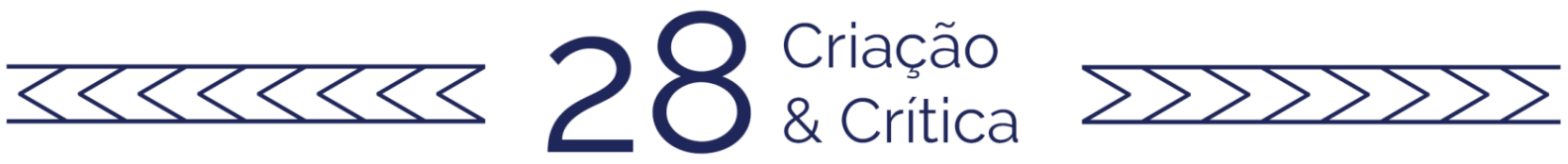

(CARSON, 2015). En la tradición literaria clásica se cruza el tema del barco con lo amoroso, la imagen antigua de lo erótico con la ética cristiana, las tormentas con la oscuridad y lo espectral, el desorientarse en el camino. Se apela al erotismo y al barroquismo presente en Ovidio, en los sonetos y anti-textos de Petrarca, o bien, en Tasso, en los que aparecen motivos erótico-amorosos, buenos y malos amores, puertos vinculados a lo amoroso, a los celos, a la pasión y a los amores fugaces, a las tormentas en los que los amores navegantes o volátiles entran en los paradigmas marítimos de velar, volar, amar y en la realización de los deseos sexuales, metáforas eróticas ligadas al deseo (KNAUTH, 1986/87, pp. 95-108) ${ }^{17}$. A través del navío se urde una historia amorosa, deseada, irreal, de los orígenes junto con la condición intelectual del sujeto $h(g)$ uacho/huérfano dado que es poco probable que esta mujer sea una amiga comprensiva y generosa del navegante. En la Leyenda del Linyera convergen estos aspectos del devenir clásico marítimo montado en el aparato moderno y vanguardista, hacia la apertura barrial de lo introspectivo, al borde del Riachuelo (STRASSBRUGER, 2020):

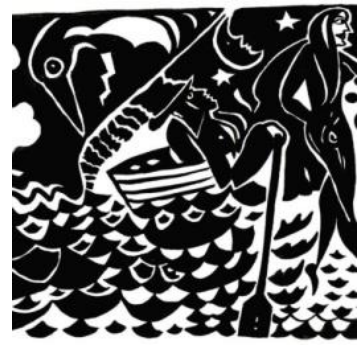

(B) Ricardo Mosner, El Linyera (2020).

En general, se asegura que el sujeto náufrago del siglo $\mathrm{XXI}$, ni femenino ni masculino ${ }^{18}$, heredera discursos propios de una modernidad gelatinosa, urbana, de "acuarios humanos", una modernidad que se plantea acuática, basada en el imaginario de criaturas marítimas y de sirenas maniobrando el redescubrimiento de un espacio alegórico submarino de la Atlántida barrial del siglo XIX (OLALQUIAGA, 1998, p. 174). Esto último se observa en el contexto lunfardesco del tango nómade que encalla en la porteña melancolía del barrio de inmigración genovesa de La Boca, desde un barrio parisino y de los icónicos sonidos sacros del bandoneón en Europa ${ }^{19}$. Entre los tonos de vanguardia, lo

\footnotetext{
17 La realización amorosa y melodramática se inscribe en las velas y en las jarcacias junto con la imaginación textil del (des)cosido, implícita en Alberti Marinero en tierra: "Del barco que yo tuviera,/ serías la costurera.// Las jarcias, de seda fina;/ de fina holanda, la vela/ - ¿Y el hilo, marinerito?/ -Un cabello de tus trenzas." (KNAUTH, 1986/87, p. 105). Se connotan los pechos, los vestidos y peinados de las damas rococó, inscriben su significado fálico como modos eróticos del ser-siendo, asimismo el barco junto con sus imágenes de navegación, vela, mástil y quilla (IBÍD., pp. 109-108).

${ }^{18}$ La ventajosa imagen dual, en femenino - sirena en soledad/ aislada - y en masculino, dotado para el amante abandonado enloquecido por los (en)cantos de la musa arrabalera.

${ }^{19}$ En la historia del tango reaparece el vínculo a la cultura germana a través del icónico instrumento musical, el bandeoneón y el clarinete. En Borges lo sefardí-judío está presente en los suburbios de la Babilonia bonarense, en la milonga y en el tango (Borges, 1977). Dentro de la gaveta tanguera de sastre, se guarda un conjunto desordenado de cosas, una heterogeneidad del mundo y una lengua pura prebabélica. El clarinete acuna la historia del bucólico semidios griego Pan. Gasparri hace referencia a "Bartolo tenía una flauta" acerca de la "orgiástica diablura", basándose en Borges, y a su escondida connotación erótica. (Gasparri, 2011, p. 176). Melingo menciona esta premisa de tono "erótico" en una entrevista publicada en el
} 

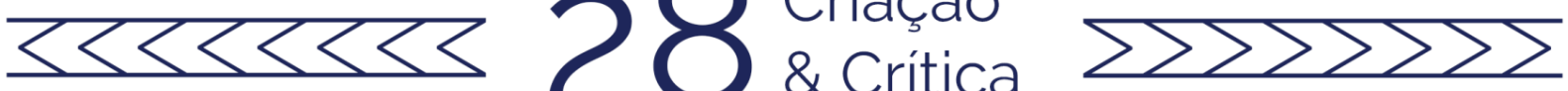

marginal barrial se describe en Borges como un precario y lúdico escenario del dandytanguero, Buenos Aires en su fervor se muestra como una ciudad del azar, de "naipes" dispuesta al juego de lo popular, al entrelazar la tradición literaria con el cafúa, lo lúdico con la imagen del Arrabal (1923) borgeano que amanece al sonar de los relojes de tableros de ajedrez citadino: "El arrabal es el reflejo de nuestro tedio./ [...] El pasito precario,/ desesperadamente esperanzado,/ salpicaba las piedras de la calle/ y divisé en la hondura/ los naipes de colores del poniente/ y sentí Buenos Aires" (BORGES, 1975, p. 45). Pizarnik programa en "Dédalus Joyce" de La tierra más ajena (1955) al hombre funesto, frágil, sin alimento, un hombre de altos mares, un hombre en los ciclos de la muerte, de ríos profundos, al hombre de ojos anti-miopes, al hombre sin miedo de pluma en mano, un hombre barco-blanco (PIZARNIK, 2015, p. 31).

Este felino dandy porteño, con su refinada nota precaria, nace del guitarreo de sonidos sucios e imperfectos (PERRIN, 2012). Posee conocimientos inconscientes de moda transplantados a la tierra criolla del europeizante baudelairiano "Príncipe negro de la elegancia", compuesto en su aparato cultural de una nota narcisista y erótica, en tanto un héroe de la decadencia, que cultiva el habitus de ser moderno y, al mismo tiempo, de transgredir este mismo estado (BIRLANGA, 2007). Esto último resalta la heroificación del presente, la moda posee como función misma y su transfiguración en la imagen mítica de un pasado perdido del guapo, su actualización por medio de la imagen gótica, libertina y sadista del vampyr ${ }^{20}$ (KOCZKAS, 2016, p. 47), transgredida por el tango bastardo de Melingo, y esto se actualiza por medio de la figura del mendigo-criollo, del Linyera (IBÍD.; GASPARRI, 2011, pp. 177-178). El discurso de la moda miran hacia los autores de Boedo, hacia Rusia, Alexis Tolstoi, Gorki, Dostoievski y Andreiev que propagan la idea de Boedo, del jorobadito que vende diarios; de la costurera que vive en un conventillo, víctima de un libertino; una pobre muchacha empujada por la necesidad económica (ARLT, 2011, p. 19). Desde los espacios literarios de la vanguardia criollo-argentina, Borges describe en El Títere (1965) al vistoso e icónico compadrito del conventillo, bailarín y jugador que podría ser su doble: "Atildado en el vestir,/ Medio mandón en el trato;/ Negro el chambergo y la ropa,/ Negro el charol del zapato" (BORGES, 1975, pp. 299)21. En Mayo 20, 1928 (Elogio de la sombra, 1969) plantea el devenir criollo invulnerable y melodramático, un sucida, mas antes de darle término a los acontecimientos que turban su vida: "Se alisará el pelo, se ajustará el nudo de la corbata (siempre fue un poco dandy, como cuadra a un joven poeta)" (BORGES, 1975, pp. 328-329).

periódico el Perfil: "Yo toco vientos, como el clarinete, el clarinete bajo, las cornamusas". Acceso: el 11 de abril 2020.

${ }^{20} \mathrm{La}$ influencia del decantismo en los primeros movimientos de vanguardia y el navegante, se suma la imagen del "XXXI. El Vampiro": "y el jugador tenaz al juego,/ y como el borracho a la botella,/ y a los gusanos la carroña,/ -sí, maldita, maldita seas!" (BAUDELAIRE, 2015, pp. 170-171). En "Las metamorfosis del vampiro": "La mujer entretanto, con su boca de fresa,/ retorciéndose igual que una serpiente de fuego,/ y moldeando el seno en su férreo corsé/[...]" (BAUDELAIRE, 2015, p. 529). De igual modo presente en la colección 2020 de Jean Paul Gaultier.

${ }^{21}$ El artículo de Graziano en La Tercera comparte muchas lecturas de Borges en las formas de llamar el trabajo de Melingo en Oasis (2020). 

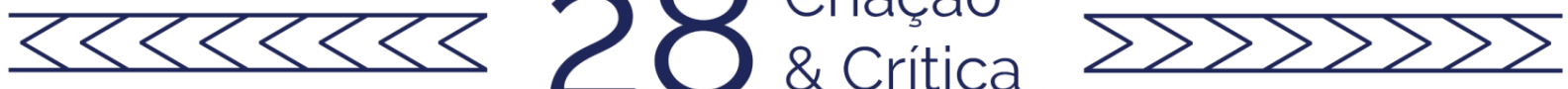

Dentro del aparato postvanguardista de la construcción de las masculinidades, en otros términos, de subjetividades identitarias masculinas heteronormativas que, desde el punto de vista vanguardista, se las denomina "viriles"22, se trazan a partir de las letras del tango, de su filosofía, literatura y visión de vida imágenes unidas al anacrónico modelo histórico del "guapo" hacia el estereotipo masculino nacional (GASPARRI, 2011, pp. 179178). La moda llevará bordada la historia tanguera desde la tela, la marca de Carlos Gardel a partir del traje: hacia 1920 y hacia 1933 la "tangomania" exigía el traje típico florido de gaucho, o bien, hacia 1932 el smoking; para las damas el uso del traje largo y negro, desde el percal a la seda, hasta la recuperación del tango en 1990 para la preservación de la memoria tanguera-textil a modo de live stil desde el punto de vista sociológico (habitus) ${ }^{23}$. Esta tanguera-textil memoria juega rabiosamente con personajes del populacho, el sastre, así esboza Roberto Arlt a uno de sus personajes, de la chusma argentina: "Era alto y enjuto. Sobre la abombada frente, manchada de pecas, los lustrosos cabellos negros se ondulaban señorilmente. Tenía los ojos de color tabaco, ligeramente oblicuos, y vestía traje marrón adaptado a su figura por manos poco hábiles en labores sastreriles" (ARLT, 2011, p. 92). Bajo esta perspectiva, se refuerza el trabajo de memoria y performancia de Melingo, su live stil reforzado por la moda en forma de recodificación de imágenes vinculadas a la historia del tango y su transgresión en las sonoridades del siglo XXI. Desde el punto de vista metodológico, se aplica la imagen de una telaraña intertextual e intermedial cuyos puntos nodales o dispositivos de análisis, entrelazan disciplinas orales, visuales y escritas. En particular, se sostiene este modelo para el análisis de los dispositivos visuales, textuales y audiovisuales ${ }^{24}$. La telaraña ${ }^{25}$ como imagen visual posee nodos en los que se adhiere el hilo seda e interconecta textos e disciplinas, por ello, este análisis favorece la interconexión entre imágenes, textos dialogando con estas imágenes, vídeos y letras del tango-canción con fuentes literarias. El tango en su totalizadora dimensión elabora a partir del concepto de "sensibilidad nueva", un viaje dantesco al Paraíso o al infierno del poeta-endemoniado que logra entrar a las aguas turbias del submundo. En el caso de Melingo, el poeta-trovador, llega tras un

\footnotetext{
${ }^{22}$ La diferencia entre el término "masculino" y "viril" se entiende desde terminologías heteronormativas, que denomina la construcción de masculinidad desde parámetros de la norma, y, por otro lado, el concepto "viril" arropa, bajo términos textiles, las discontinuidades de las vanguardias como término heredado del blindado y automovilístico futurismo de Marinetti, presente en la telegrafía sin hilos de Roberto Arlt (2011).

${ }^{23}$ Me remito a la exposición realizada en el "Museo de la Historia de la Moda" (2019) se vincula la moda con la historia del tango, ver: https://museodeltraje.cultura.gob.ar. Acceso: el 28 abril 2020. De igual modo, en Boquitas pintadas se hace referencia al tango, la milonga, la modistilla, a la ropa y a lo textil (PUIG, 1969).

${ }^{24}$ Carggiolis (2015) aporta al análisis literario arácnido de relaciones intertextuales basadas en Genette, apela a un análisis de principios interpretativos de los medios y textos. Se atiende la construcción visual, el lenguaje audiovisual y de vídeos en diálogo con las figuras de la opera y Oasis (2020) a partir de una vanguardia textil con proyección hacia los medios del siglo XXI.

${ }^{25} \mathrm{La}$ imagen emblemática de la telaraña/textil fantasmal acompaña varios de los motivos literarios en la poesía de Pizarnik: enredar, costura, trenza, vestidura, retazo, envoltura, tela, algodón, pliegue, velo, seda, hilo, hilar, enlazar, amarrar, engarzar, mortaja, harapo, coser, textura, araña, atar, arpillera, entre otras terminologías. Esto contextualiza otros campos semánticos náuticos y siniestros aparecidos en Oasis (2020): dientes, pirata, estrella, nenúfar, mar, ancla, barco negro/ blanco, navegante, naúfraga/o, naufragio, perro, olas, cantar, corsario, muerte, cofre de piratas, entre otros.
} 

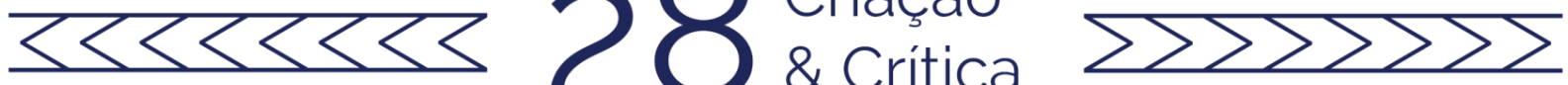

largo viaje a Oasis (2020). Este trayecto se considera de profundidad intangible, espiritual, iluminada, alegre, y de una beatitud divina, propia de una nueva sensibilidad enlazada de manera amorosa con la práctica bastarda/lunfarda, del hampa popular (DANTE, 2014, p. 28). Esto defiende las propuestas de una vanguardia lumpen, afectiva, sensible, y, también doméstica ${ }^{26}$; de esto surge una ruptura de estructuras literarias, filosóficas y culturales, se la hace subalterna, marginal, o bien, en otros términos lumpen o trash. El lunfardo pasa a ser una lengua mixta del harapo y de trapos, un habla-quilt, es decir, un habla-textil de la conexión trozos irregulares de diversos substratos lingüísticos de carácter urbano, una lengua de mendigos y vagabundos, un lenguaje harapiento, heredero de la jerga de los barcos. Menlingo se apropia de palabras en lunfardo, actualiza un catálogo lunfardo en su producción musical imprimiendo un "Glosario lunfardo" (CORAZÓN \& HUESO, 2011) a modo de documento de memoria y hace del registro suyo otros cuantos conceptos: "guita", "bondi", "mina", "bulín", "cotorro" (MELGAR, 2020). En este contexto, se deja constatar el lunfardo como una complejidad y repertorio lingüísticos, que, según Borges, denomina una: "tecnología de la furca y de la ganzúa" (GOBELLO, OLIVERI, 2005, p. 12). Aplicadas estas ideas vanguardistas a la cultura popular del siglo XXI, el lunfardo en las letras del tango-rebétiKo se construye en 2020 postvanguardista desde "una oralidad cultural e imaginaría popular", avizora un malestar en la cultura, la modernidad construye mapas mentales y locales, esto como fenómeno cultural-mediático se produce como consecuencia, según Martín-Barbero (1999):

Ante la desazón y el desconcierto de los adultos vemos emerger una generación "cuyos sujetos no se constituyen a partir de identificaciones configuras, estilos y prácticas de añejas tradiciones que defienden la cultura sino a partir de la conexión-desconexión (juegos de interfaz) con las tecnologías" (MARTíN-BARBERO, 1999, p. 35).

Bajo el concepto de una "nueva sensibilidad", las vanguardias del 20 y 30 se desarrollan bajo el amparo de una guerra de imágenes en tres periodos: a) la significación profana de la Virgen de Guadalupe ante el mundo americano a través del concepto de hibridez; b) el barroco americano del siglo XIX con los misioneros franciscanos y el barroquismo visionario de los jesuitas; y c) la recuperación actual de los imaginarios populares con nexos que enlazan las sensibilidades a un orden visual bajo el subyugo del actual (des)orden del imaginario o dispositivos culturales (MARTíNBARBERO, 1999, p. 37). El pasado atiende al presente y conforma el futuro de las producciones mediáticas (un futuro-pasado). En el caso de la imagen en tinta negra de El Linyera, figura creada también por Rodolfo Palacios, se demuestra la recuperación de la cultura visual a través de una figura retórica del desarraigo, del viaje y de su significado neobarroco, aquí góticas rioplatenses:

\footnotetext{
${ }^{26}$ Recurro a una vanguardia doméstica en sentido múltiple dado que Gobello sitúa préstamos del genovés familiar en el lunfardo junto a voces gastronómicas: tuco, fainá, chupín y otras domésticas como feta o pishar implícitas también en las letras del tango (GOBELLO, 2006, p. 16).
} 

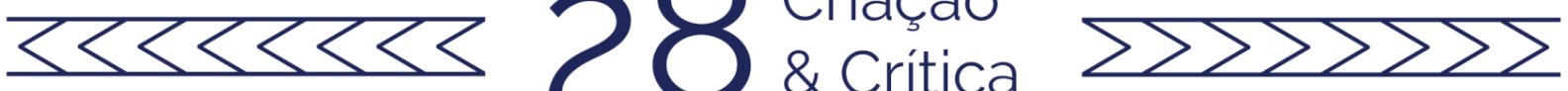

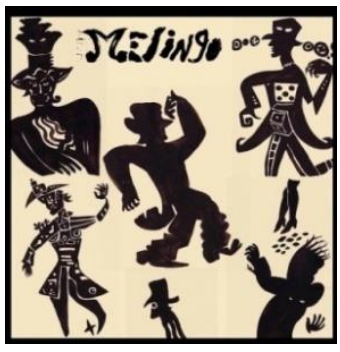

(B) Ricardo Mosner, El Linyera.

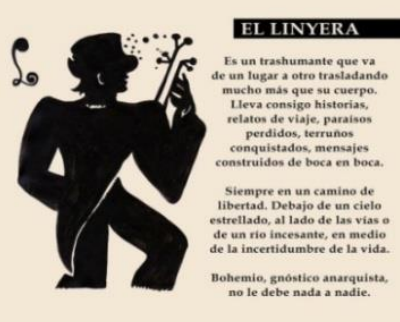

(B) Ricardo Mosner, El Linyera.

En la letra de El Linyera se distingue la temática del poeta trashumante, de paraísos perdidos como es el caso de la obra total de Oasis, de mensajes orales del peregrino que narra en libertad la aventura de la vida, del bohemio o anarquista que vive sin reglas de paso borgeanamente hacia la temida muerte ${ }^{27}$. Al utilizar una metodología de trabajo se necesita estructurar los temas iniciáticos bajo los tópicos del viaje en el lado A de Oasis que parten del título "Oráculo" y "Búsqueda", para continuar con el tangocanción "Caminito", "Camino y hablo solo", "Camino rebétiko" hasta acabar con "Navegantes", en cuyas letras reaparece el tema del "camino", analizado aquí como una parte del laberinto del lado A de Oasis. En el lado B se sintetiza en el construido laberinto del lado A el tópico de la perdición y la muerte por pasión, en tanto pastiche de "caminito", que parte con la figura de una sirena que trae la música y la perdición del héroe, "Hécate". Se continúa con la experimientación musical abismal titulada "Cavelier King Charles". Se simboliza el punto culminante de la vida del héroe épico, El Linyera, a través de la historia narrada en "El blues rebétiko de 7 vidas"28; luego, se avanza hacia el tango "¡Está vivo! ", posteriormente, se construye desde sonoridades y textualidades naif cercanas a la imaginería de Xul Solar, un idílico lugar neocriollo llamado "Oasis"29 (MOLLOY 2018). Se cierra de modo surrealista la salida onírica del laberinto con el título "El sueño del éxodo" con los motivos de la muerte y la pasión de El Linyera por la bailarina (MELINGO 2020). Finalmente, la trilogía El Linyera (2014) y Anda (2016) entona el Bildungsroman con variados aspectos de la picaresca por sus réplicas paródicas. Imagen vanguardista por antonomasia, el laberinto, en el tango-canción "Caminito" (1926), letra de Gabino Coria Peñaloza, reaparece en Oasis (2020) sólo en instrumental a través de su música con melodía griega, abordando el clásico tema del laberinto de Creta desde la memoria del

\footnotetext{
${ }^{27}$ La idea de la libertad y el peregrino que transmigra, el pregonero o el trovador, tiene su origen en la tradición medieval, mas encontramos estas terminologías en el esoterismo representado en las cartas del tarot con la imagen de El Loco, y en las estéticas surrealistas reaparece la terminología del viaje y del orden innato del camino bajo el paradigma lúdico del ensueño y las ánimas. La imagen mítica de El Linyera proviene de "La canción del Linyera" en "El Linyera", 2014, editado por Melingo.

${ }^{28}$ Según Daniel Melingo, la grafía de "rebétiko", "k" en vez de "c", es una adaptación del alfabeto griego. Información vía WhatsApp. Acceso: 06. Diciembre 2020.

${ }^{29}$ La letra de Oasis compuesta por María Celeste Torres se produce en cooperación con su hijo Félix Melingo. La letra la compone junto con el escritor y periodista Rodolfo Palacios, la historia de los diversos personajes la convocó con: Enrique Symns, escritor (figura: Henry el Adivino), Fernando Noy, actor, performer, poeta (figura: El Malevo Noy), Andrés Calamaro, compañero de Los Abuelos de La Nada (figura: El siete vidas), y Vinicio Capossela (figura: El cafishio cocoliche). Colabora con Stefanie Ringes (Lions In Love), Miguel Zavaleta (músico popular argentino) y el investigador de lunfardo, Luis Alposta (RAMOS, 2020).
} 

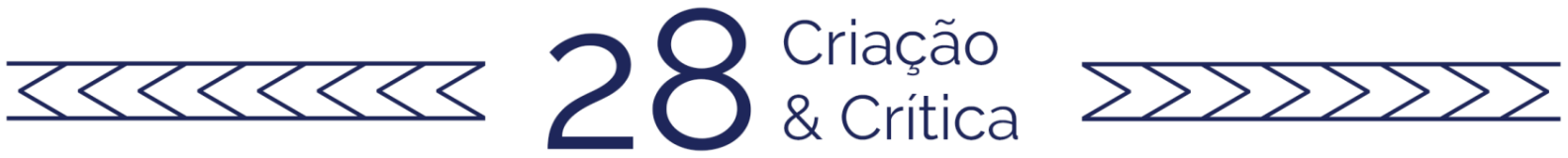

devenir de un Eterno Retorno del caminito que vuelve. Un laberinto, cuyo hilo se retoma de variadas formas en la historia del tango y en su literatura, y aquí se acentúa el modo de mostrar al sujeto en soledad, en tanto peregrino "loco" que habla y canta solo en el camino de la vida. Esto aborda el devenir del sujeto en el laberinto sonoro en sí mismo, así nace por este "laberinto-caminito" el personaje "El 7 vidas" creado por Andrés Calamaro ${ }^{30}$. Se traslada en el canto amoroso dirigido a Ariadna, que en Oasis encarna en el personaje siniestro de "Hécate"; lo amoroso se ve en la bailarina, se expresa a través de la primera persona singular, yo, en sensibilidad a cualquier referencia de espacio y tiempo, en libertad de ser/estando (en tiempo presente). El peregrino se baja de la barca para continuar en la desgracia rítmica hasta llegar al cierre musical, al idílico "Oasis":

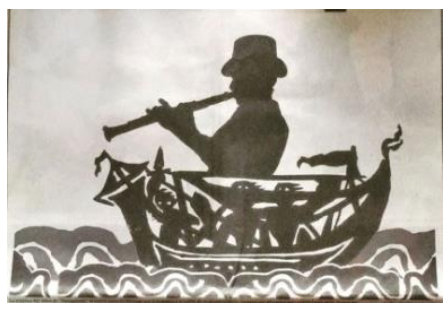

STRASSBURGER, Juan M. (2020): "Gótico rioplatense. La nueva escena musical que viene de las entrañas", en: La Nación.

El Linyera transporta su tripulación en la barca que navega sobre un mar entretejido de mitologías y cosmologías, en "EI mar" de Borges se menciona una imagen onírica, mitológica, cosmológica del mar, del viento, del abismo, resplandor, azar, de la luna y del fuego y la hoguera (BORGES, 1977, p. 275). El navío en Oasis tiene un significado familiar que se sostiene en la idea de la feminización del océano, se atiene al movimiento y al amor, a una definición política democrática, en cuya superficie se ejercen los derechos inicuos, pelearse, devorarse, transportar los horrores terrestres (OLALQUIAGA, 2007, pp. 142-143). Se trasladan personajes de la ópera comunitaria: la figura icónica del aventurero, cafishiol pirata de alta mar encerrado por herencia familiar, melancólico y pícaro. Esta figura conquista y arriba en el coliseo de una iglesia medieval parisense representada en un texto en francés sobre L'Église Saint-Germain-des-Prés pintado con personajes diversos en torno a la escena piratesca representada en Oasis (MOSNER, 2020). Esta figura dialoga con "Navegantes" en la que aparecen los amantes desenfrenados, ella en descontrol y el amante, un pirata/ Cafishio, ícono de los discursos subalternos, bajo la impronta de las barajas del destino, en la locura pasional, perdidos ambos entre risas y llanto (MELINGO, 2020).

\section{Construcción de subjetividades de género}

El destino de las naves y de los pensamientos es muy parecido: confiados, se lanzan a navegar por territorios desconocidos, intentando llegar a su meta siguiendo una línea lo más recta posible. Sin embargo,

\footnotetext{
${ }^{30}$ En el punto siguiente se estudiará la figura junto con partes de la ópera en Oasis (2020) y que será analizada más abajo en el punto de la "Construcción de subjetividades".
} 

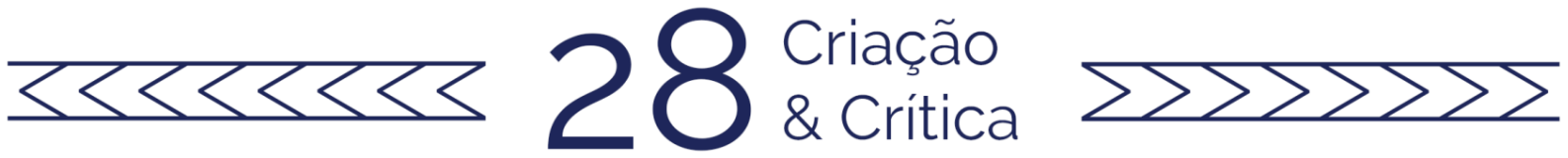

una vez sobre las olas, empeñados en su viaje, se encuentran asediados por hechos sorprendentes: pesadillas de monstruos marinos, tormentas imposibles de prognosticar, olas gigantes que los voltean inmisericordes y engullen con frecuencia sus frágiles cuerpos sin previo aviso. (OLALQUIAGA, 2007, p. 11)

La imagen de la navegación conecta ideas relacionadas con lo desconocido, con territorios nuevos que avanza directamente hacia su objetivo, tal vez esta imagen marítima ayuda a vincular las complejas construcciones de subjetividades de género: se habla de sus discriminaciones, en tanto monstruos marinos, de tormentas imposibles de prognosticar al asumir una serie de discriminaciones, o bien, de avistar olas gigantes con violencias de género. El naufragio de teorizar lo binario, lo unitario y provoca crear en El género en disputa (2014), monstruos y navíos que se asoman a encallar en el ámbito de la teoría cultural en la que subyace el término "subversión" para cualquier tipo de distancia de la "realidad de género" con objeto de hablar en mejor de los casos de un flujo de subjetividades de género (BUTLER, 2014, pp. 7-33). Para determinar subjetividades de género y no limitarlos a los paradigmas heteronormativos, a la norma - ni en femenino ni masculino -, propongo acercarnos a este respecto desde la metáfora textil que aborda la idea del flujo de identidades genéricas a través de la imagen de una vestimenta griega, la toga, que es igual tanto en figuras femeninas como masculinas. Es una toga austera, sin adornos, sencilla, no presenta prácticamente costura, drapeada, y en los bordes es geométrica diseñada de una tela no cosida que construye identidades de género tanto femeninas como masculinas. Esta tela simple enseña el flujo de las identidades de género, en el caso de Oasis, se muestra junto al personaje de Fernando Noy, El Malevo Noy/ La Chamana:

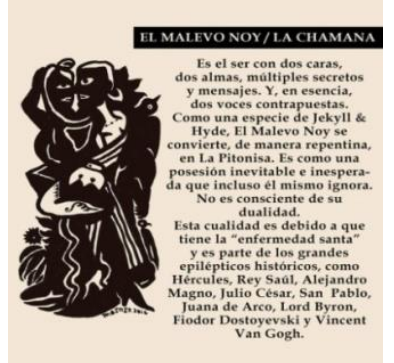

®Ricardo Mosner, El Malevo

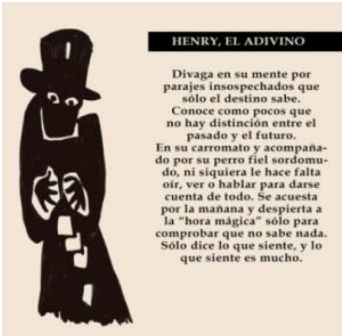

® Ricardo Mosner, Henry, el adivino 2020.

Noy/ La chamana, 2020.

El Malevo Noyl La chamana es una figura de dualidad en oxímoron unidas en una figura, esta cualidad provoca una cosmovisión del mundo vertical, de jerarquías, femenino-masculino, lo femenino masculinizado y lo masculino femenizado, en un eterno diálogo a(r)mo(roso)/-nioso. La transformación de este ser bipartito caracteriza a esta figura, El Noy-cuchillero se encarna en La Pitonisa-gitana, adivina del destino de El Linyera, mientras que El Noy trae el juego, el azar, la vida nocturna del tango y del 

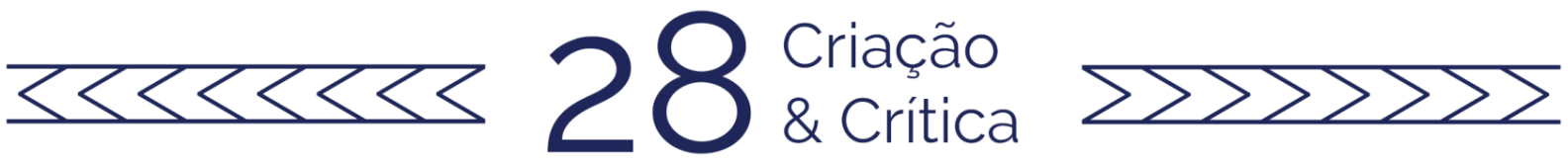

cabaret, es parte del imaginario arrabalero borgeano/ arltiano. Esta dualidad, según Fernando Noy ${ }^{31}$, es la que construye el tango rebético, la masculina del orillero, arrabalero, la parte porteña y la parte de la hechicera, de la embustera, es la del arte celestinesco de predecir el futuro, es quien tira las cartas del destino, el lado griego (MELINGO, 2020b). Esta figura está emparentada con la idea del flujo de las identidades de género y con la yuxtaposición de lo femenino y lo masculino a través de la metáfora y fusión del tango rebétiKo y de la toga griega, prenda unisex.

Como parte de la construcción de la "nueva sensibilidad" se destaca la significación de imágenes religiosas y paganas ${ }^{32}$ interrelacionadas con la afección, lo hospitalario, lo clínico, la discursos de higiene. Este es el caso de El Malevo Noyl La chamana, quien sufre de una "enfermedad santa", posee una patología bendita (GOBELLO, 2006). Esta figura compone la ópera total recogida en la barca de Melingo, dentro de ella está embarcada la patrona mítica y el devenir militar de Buenos Aires, Juana de Arco (PERLONGHER, 1997, 17). Lo religioso y lo pagano se funden en un ícono de género transgresor de paradigmas de la época, una mujer soldado, cuya historia bélica y soledad demuestran fuerza debido a las duras pruebas inquisitoriales querían quebrantarla, finalmente es abandonada hasta por Dios, una mujer rústica, sufrida, sincera (ARAUZ MERCADO, 2019). Otras figuras de la ópera total abren el discurso de Oasis (2020), que introducen el lado B del disco, son "Hécate" y "El 7 vidas", diseño de Ricardo Mosner:

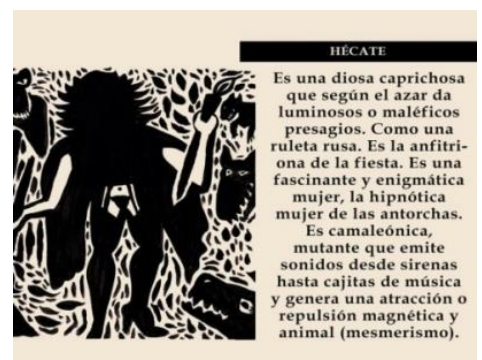

® Ricardo Mosner, Hécate, 2020.

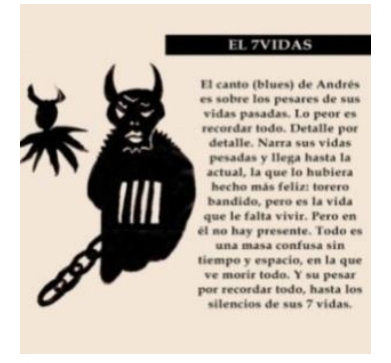

(B) Ricardo Mosner, El 7 vidas, 2020.

A la mallarmeana "Hécate"33, en tanto una Circe homeriana, se le describe como una "diosa caprichosa", "camaleónica", "macabra", "mutante que emite sonidos (desde sirenas hasta cajitas de música)". Esta posee la misma dualidad del personaje de

\footnotetext{
${ }^{31}$ Las entradas de los textos/narraciones de las figuras que forman parte de la ópera Oasis y la autoría de los textos se encuentran en la página de Daniel Melingo: https://www.facebook.com/danielmelingo, 2020.

32 En El juguete rabioso (Arlt, 2011) se sostiene la relación entre lo materno (popular) y las manualidades textiles, junto con la idea del lunfardo como práctica haraposa y religiosa: "Mi madre cosía en otra habitación y mi hermana preparaba sus lecciones. Me dispuse a leer. [...], tenía las siguientes obras: Virgen y madre de Luis de Val, Electrotécnica de Bahía y un Anticristo de Nietzsche. Virgen y madre, cuatro volúmenes de 1.800 páginas cada uno, me lo había prestado una vecina planchadora." (ARLT, 2011, p. 161). En Santa milonga (2003) se destaca la iconografía religiosa en el título a modo de producto híbrido construye un "altar de la música rioplatense sin llamar".

${ }^{33}$ En las barajas del tarot representa La Luna, práctica vanguardista, por ejemplo en la de Xul Solar, entre otros.
} 

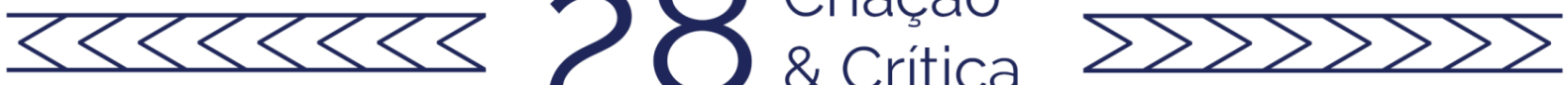

Fernando Noy, atracción y repulsión, premia y castiga, muerte y traición, es un impedimento para El Linyera; se dice que los hombres caen rendidos con sus sonidos de sirena ${ }^{34}$, es ambigua, tiene el don de hundir barcos, es una fémina transgresora, lleva una antorcha, y está acompañada de un perro de tres cabezas. Es una figura que indica perdición, también significa lo prohibido (vive un romance con el adivino Henry), creada por Enrique Symns, es uno de esos personajes híbridos, pertenecientes al submundo. Encarna la parodia de los cantos del don de sirenas, se habla de "sonidos" de clarinete y perdición para el escucha ${ }^{35}$. Esta figura está entretejida románticamente con "Henry, el adivino", quien conoce parajes insospechados, posee la dualidad temporal: se acuesta por la mañana y levanta a la "hora mágica" (MELINGO, 2020b). En Oasis atiende "Hécate" un espacio de lo siniestro, diosa sentada en un trono situado en marismas calificadas por el terror, arrastra al héroe junto con los perros hacia su perdición; se muestra una figura oscura cuyos "dientes de oro" están cubiertos por un terreno pantanoso, barroso (MELINGO, 2020). La escritura oscura de esta figura se percibe junto a perros, presentes en la piratería así como en aquellas letras con motivos escatológicos. Hécate, devoradora de marineros, acompaña con hechizos a "Cavalier King Charles" - en Oasis (2020) es sólo instrumental -, a quien convierte en perro, en servidor; se trasladan en un navío después de la masacre a un viaje infernal que emprende El Linyera. A través de la figura "Hécate" se manifiesta una relación de poder con la connotación atribuida a la sexualidad y a la ambigüedad, dualidad en su naturaleza. Es una relación externa o arbitraria (social y culturalmente establecida, el ambiente porteño de proxenetas y bandidos), articulada en el paradigma de represión y dominación bajo la idea de una multiplicidad de cualidades que irrumpen para atraer a los marineros, esclavizarlos, dominarlos y encantarlos a través de sus brujerías, lo que implica de igual modo violencia de género, sadismo, dominación/sumisión, violencia y humillación (BUTLER, 2014, pp. 198-204; GOBELLO, 2006; KOCZAKAS, 2016, p. 47).

En "El blues rebétiko de 7 vidas" (OASIS, 2020) se tematiza el padecimiento del hombre y la incomprensión que le produce su medio, en tanto un enorme y sabio insecto kafkiano, que lo recuerda todo, un esclavo del tiempo, que paga su culpa atado a grillos, vive su condena en la tiranía de la culpa. En la sociedad mediatizada el padecimiento melodramático que adquiere el saber y los nuevos modelos culturales de ver/leer las sonoridades plasmadas en otras letras latinoamericanas llevan, por ejemplo, a producciones músico-literarias de Cortázar en El perseguidor: el influjo del jazz y Johnny Carter (Charlie Parker, saxo) ${ }^{36}$. En el caso de la máquina musical y la tristeza agónica del blues, se reconoce un espacio algo huidizo y rupturista; de igual modo, se habla de flujos sonoros que indican libertad, de un espacio laberíntico circular que agencia la indagación

\footnotetext{
${ }^{34}$ Hécate posee una caja de música que hace resonancia en el tiempo; la "Caja de música" de La moneda de hierro (1976) de Borges resuena: "Música del Japón. [...]/ Que en el tiempo repiten una trama/ Eterna y frágil,/ [...]." (BORGES, 1977, p. 520).

${ }_{35}$ Pizarnik muestra el dualismo existente en los colores rojo-negro con objeto de mostrar el contraste, en "En esta noche en este mundo. Sobre un poema de Rubén Darío" (PIZARNIK, 2015, p. 371).

${ }^{36} \mathrm{El}$ tango es un lugar de extrañas simetrías a través del tema con la pobreza, Carlos Gardel y el boxeador Justo Suárez reflejan el ambiente urbano y las ollas populares (ARLT, 2011; CORTÁZAR, 2003, p. 13).
} 

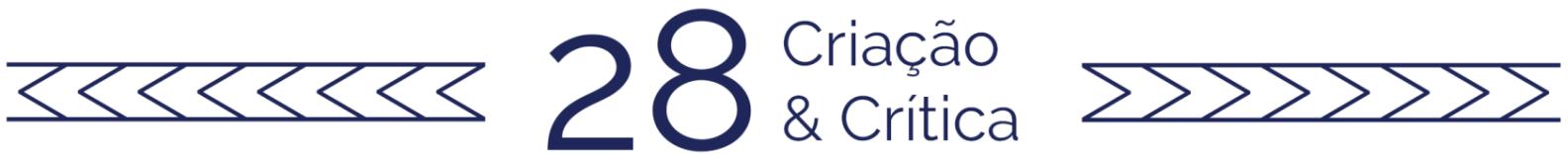

del sujeto en todos los terrenos, de la geografía interna, de la memoria, de la temporalidad y del flujo-tiempo, de la condición del yo, masculino/femenino subalterno consciente de su contexto socio-cultural en función de sistemas discursivos.

\section{Conclusiones}

Mallarmé en "Brisa marina" (MALLARMÉ, 2013, p. 51) expresa una despedida, un adiós "supremo", con esperanzas de zarpar a nuevas tierras sin la esperanza de llegar a nuevas tierras; se le canta al marinero, a quien solo navega a nuevas tierras en pleno Decantismo. En dos orillas signadas por contextos históricos distintos, el del Viejo Mundo y el del Nuevo Mundo/ de los arrabales, emergen manifestaciones de la cultura popular cargadas con las historias de marineros con las letras del tango. Proyectan lo criollo y lo construyen con sonoridades emparentadas con el rebético o el fado, también de origen marinero, hasta canalizar una propuesta postvanguardista. Mediante estas tramas discursivas se sopesan particularmente dispositivos visuales, textuales y discursividades destacadas en los estudios de género mediante la metáfora textil, la toga. La fuerza expresiva de figuras mítico-nacionales recibe abrumadoras masas de migrantes, el tango desempeña una función integradora: El Linyera, Juana de Arco, Julio César, el "guapo", la costurerita, Jack el Destripador, entre otros. En este sentido, Oasis (2020) muestra un aparato rico en dispositivos culturales y de género, lo que salta a la vista aquí es la dualidad ejercida por las figuras atentas al recurso por antonomasia tanguero: el oxímoron. Esta misma forma retórica, se atiende para determinar la función de las dos corrientes del "tango rebétiKo" en el estado de la dualidad-fusión, del femenino y del masculino, por medio de la figura El Malevo Noyl La chamana, de Fernando Noy. En la composición de una ópera total se advierte que el dialogo intermedial e intertextual gesta un estimulante circuito de análisis cultural manejando un aparato metodológico desde el navío, a partir de la navegación dado que estos aspectos irrumpen en los estudios de género. Una opera aperta en la que circulan no sólo el origen vagabundo de su lenguaje el lunfardo -, el peregrinaje originario de sus instrumentos, el nomadismo de sus sonidos así como las relaciones intertextuales en el aparato cultural de sus letras. Esta caja negra cultural popular comunitaria se va definiendo aún más en las letras del tango "Seamos hermanos" compuesta por Dante Linyera musicalizada por Melingo: "Versos atorrantes/ ¡pa'ustedes, muchachos!/ Qu'entuavía s'ecurdan/ de anis d'entusiasmo/ pa'ustedes, que siguen creyendo que semos,/ que semos hermanos...//" (MELINGO, 2011). La gaveta del tango propone aspectos populares y remite a temas vinculados con preo

cupaciones del cotidiano, del trabajo y de robos, y en estas mismas desgracias, se entretejen textos de Evaristo Carriego, en las letras de la milonga Ritos en la sombra de Melingo (MELINGO, 2011). El largo y poderoso relato masculino nacional y popular basado en un modelo social hacia las construcciones de masculinidad nacional. De igual modo, se argumenta que desde las relaciones heteronormativas se establecen paradigmas conflictivos en vínculos intergenéricos (GASPARRI, 2011, pp. 2011-2012). 

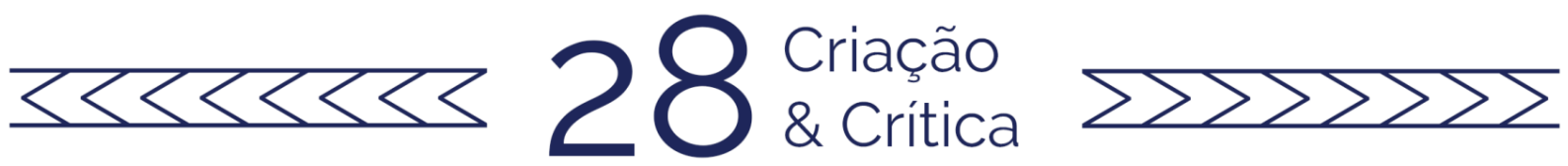

Rosas en rebétiKo sugiere partir de lo familiar, de textualidades inmersas en marmelleanos de vestidos tangueros de encaje con rosas, de piratas y de desenfrenos pasiones.

\section{Referencias}

ARAUZ M., D.. "La pasión de Juana de Arco". En: Cuestiones de género: de la igualdad y la diferencia, $N^{\circ} 14,2019$, pp. 751-761.

ARLT, R.. Los siete locos. Madrid: Cátedra. 2011.

---: El jueguete rabioso. Madrid: Cátedra. 2011.

BIRLANGA T., J. G.. "Baudelaire y la moda. Notas sobre gravedad de lo frívolo". En: Revista Bajo Palabra, Nr. 11), 2007, pp. 13-21.

BORGES, J. L.. Obra poética, 1923-1977. Buenos Aires/ Madrid: Emecé/ Ed. Alianza. 1977.

BUTLER, J.. El género en disputa. El feminismo y la subversión de la identidad. Barcelona: Paidós. 2014.

CARGGIOLIS A., C.. "El texto tejido en La amortajada de María Luisa Bombal". En: ARECO, M.; LIZAMA, P. (eds.). Biografía y textualidades, naturaleza y subjetividad. Ensayos sobre la obra de María Luisa Bombal. Santiago: Ed. UC, 2015, pp. 117-138.

CARSON, A.. Eros. Poética del deseo. Madrid: Ed. Dioptrías. 2015.

CORTÁZAR, J.. Las armas secretas. Madrid: Cátedra. 2003.

DANTE, A.. Divina Comedia (Selección). Madrid: Cátedra. 2014.

GASPARRI, J.. "Che, varón. Masculinidades en las letras de tango". En: Caracol 2. Varia. 2011.

Disponible

en:

https://www.researchgate.net/publication/281007509_Che_varon_masculinidades_en_las _letras_de_tango. Acceso: el 23 mar. de 2020.

GOBELLO, J.; OLIVERI, Marcelo. Lunfardo. Curso básico y diccionario. Buenos Aires: Academina Porteña del Lunfardo. 2006.

GRAZIANO, M. E.. "Daniel Melingo: el Dr. Frankenstein del tango", La Tercera, abr.. Disponible en: https://www.latercera.com/culto/2020/04/20/daniel-melingo-el-drfrankenstein-del-tango/. Acceso: el 20 abr. de 2020.

ECO, U.. Cultura y semiótica. Madrid: Círculo de Bellas Artes. 2009.

ECHEVARREN, R.. Arte andrógino. Estilo versus moda en un siglo corto. Buenos Aires: Ed. Colihue. 1998.

HOMERO. La Odisea. Madrid: Cátedra. 2012.

KNAUTH, A.. «Défense de la littérature. Ilustraciones hacia unos estudios literarios creativos» (mi traducción del título alemán: «Défonce de la littérature. Illustrationen zur einen kreativen Literaturwissenschaft». En: Círculo de poesía. Revista de Estudios Literarios (mi traducción del alemán: Dichtungsring. Zeitschrift für 

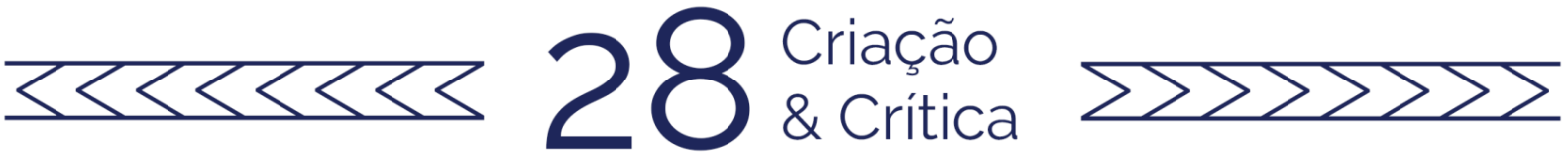

Literaturwissenschaft), 6./7. año, 1986/87, vol. 11/12 (mi traducción del alemán: 6./7. Jahrgang, Heft 11/12), pp. 88-159.

KOCZKAS, A.. "Cartografía de deseos: masoquismo y masculinidad en La última noche que pasé contigo de Mayra Montero". En: Polifonía, vol. VI, 2016, pp. 47-64.

MALLARMÉ, S.. Poesías: antología bilingüe. Madrid: Alianza Ed., 2016.

MARTÍN-BARBERO, J./ REY, G.. Los ejercicios del ver. Hegemonía audiovisual y ficción televisiva. Barcelona: Gedisa. 1999.

MELGAR, A.. "La canción es un oxímoron de música pura y poesía". En: Perfil, 2020. Acceso: el 15 de abril 2020.

MELINGO, D.. Oasis. Versión digital. París: Buda Music, 2020.

--- . Santa Milonga. Buenos Aires: EMI-Melograf, 2004.

--- Maldito tango. Buenos Aires/ París: Mañana, 2007.

--- . Corazón \& Hueso. Austria: World Village, 2011.

---. Daniel Melingo. Oasis. https://www.facebook.com/danielmelingo. Acceso: el 04 mayo de 2020b.

MOLLOY, S.. "'Añoro patria": Jorge Luis Borges y Xul Solar”. En: Cuadernos LIRICO, 18, 2018. http://journals.openedition.org/lirico/5603. Acceso: el 04 de julio 2020.

MOSNER, R.. Oasis. Ilustraciones y Teorema Mosner, 2020.

SOSSA BACARELLI, N.. "Mi noche triste: símbolo, sexualidad y ruptura. Pascual Contursi, Carlos Gardel y la configuración del tango canción”. En: Dossier: La poesía y sus bordes: filosofía, testimonio y canción, vol. 49, Núm. 2, 2019.

OLALQUIAGA, C.. El reino artificial. Sobe la experiencia kitsch. Barcelona: Ed. Gustavo Hill, 2007.

---. Megapolis. Contemporary cultural sensibilities. Minneapolis: The University of Minnesota Press, 1992.

PERRIN, J. (ed.). Melingo \& Ramones del Tango, World Village Label. Disponible en: https://www.youtube.com/watch?v=w2U-UG8Nxcw. Acceso: el 10 abril de 2020.

PERLONGHER, N.. Prosa plebeya. Ensayos 1980-1992. Buenos Aires: Ed. Colihue, 1997.

PIZARNIK, A.. Poesía completa. Barcelona: Lumen, 2015.

PUIG, M.. Boquitas pintadas. New York: Penguin, 1969.

RAMOS, S.. "El Linyera encontró su Oasis". Gramba. Disponible en: https://www.gamba.fm/el-linyera-encontro-su-

oasis/?fbclid=IwAR3WyFxuxBzXL48_c8wC22-qs-zdJ2IrRYfM-

CUVLKYe3LDuNtHQTciNsSU. Acceso: el 27 de abril 2020.

STRASSBURGER, J. M.. "Gótico rioplatense: la renovada escena musical que viene de las entrañas". La Nación, feb. Disponible en: https://www.lanacion.com.ar/espectaculos/musica/gotico-rioplatense-nueva-escenamusical-viene-entranas-nid2329050. Acceso: el 29 de abril 2020. 


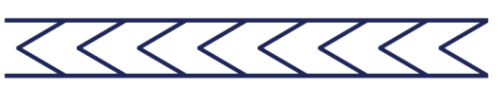

VITALE, C.. "Nuestro tango es rock y es folklore". Página 12, Buenos Aires, ago.. Disponible en: https://www.pagina12.com.ar/diario/suplementos/espectaculos/3-329332014-08-02.html. 2014. Acceso: el 07 de abril 2020.

Recebido em: 15/05/2020

Aceito em: 15/05/2020

Referência eletrônica: CARGGIOLIS ABARZA, Cynthia. Rosas en rebétiko, una opera aperta: construcción de subjetividades de género en Oasis (2020) de Daniel Melingo. Criação \& Crítica, n. 28, p., dez. $2020 . \quad$ Disponível em: $<$ http://revistas.usp.br/criacaoecritica>. Acesso em: dd mmm. aaaa. 